Article

\title{
Fuzzy Decision-Support System for Safeguarding Tangible and Intangible Cultural Heritage
}

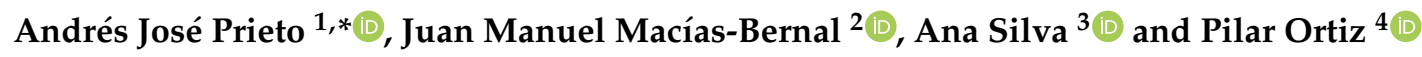 \\ 1 Instituto de Arquitectura y Urbanismo, Universidad Austral de Chile, \\ Edificio Ernst Kasper (Campus Isla Teja), Valdivia 5090000, Chile \\ 2 Departamento de Construcciones Arquitectónicas II, Universidad de Sevilla, Avda. Reina Mercedes 4A, \\ 41012 Seville, Spain \\ 3 CERIS-ICIST, Instituto Superior Técnico, Universidade de Lisboa, Av. Rovisco Pais, \\ 1049-001 Lisbon, Portugal \\ 4 Department of Physical, Chemical and Natural Systems, Universidad Pablo de Olavide, \\ Carretera de Utrera Km 1, ES-41013 Seville, Spain \\ * Correspondence: ajprieto2201@gmail.com
}

Received: 25 June 2019; Accepted: 16 July 2019; Published: 20 July 2019

check for updates

\begin{abstract}
In the current world economic situation, the maintenance of built heritage has been limited due to a lack of funds and accurate tools for proper management and implementation of these actions. However, in specific local areas, the maintenance and conservation of historical and cultural heritage have become an investment opportunity. In this sense, in this study, a new tool is proposed, for the estimation of the functional service life of heritage buildings in a local region (city of Seville, South Spain). This tool is developed in Art-Risk research project and consists of a free software to evaluate decisions in regional policies, planning and management of tangible and intangible cultural heritage, considering physical, environmental, economic and social resources. This tool provides a ranking of priority of intervention among case studies belonging to a particular urban context. This information is particularly relevant for the stakeholders responsible for the management of maintenance plans in built heritage.
\end{abstract}

Keywords: heritage buildings; functionality; decision-support system; fuzzy logic

\section{Introduction}

Ibrahim et al. [1] discuss that historical buildings are the most visible part of a country's history, reproducing cultural values, conveyed over time. Cultural heritage buildings are treasures, not just because of their architectural, aesthetic and scientific values, but also because of their inherent intangible cultural values of a particular society. They put the past into the present and keep developing culture, knowledge and other aspects. Therefore, preserving cultural heritage helps human development to be more sustainable $[2,3]$.

Nowadays, the anthropogenic pressure is becoming higher and higher due to the expansion of urban settlements and the need of connecting them, and this has been identified as being one of the most dangerous factors that is affecting the integrity and value of cultural heritage $[4,5]$. In this sense, by analysing the concept of vulnerability, it can be examined: i) in a technical/engineering approach, which is able to define, (physical) vulnerability can be seen as "degradation of an element, within an affected area by a hazard", and ii) in a social approach, is related to the characteristics of the community or population that lead to differential impacts of natural hazards [6]. The social approaches analyse the capacity of the element to preserve its integrity and functionality amid the physical interaction with the natural process of degradation $[7,8]$. This kind of procedure can be conditioned by the city's urban 
expansion (e.g. new roads, buildings), which has become a daily phenomenon in some parts or areas of European cities.

Sadegui et al. [9] mentioned that the functional degradation of buildings could be understood as a subjective issue influenced by different parameters that contain a certain degree of uncertainty. The evaluation of the functional service life of cultural heritage is a complex subject due to intrinsic vulnerabilities and external hazards. In this sense, the preservation of cultural heritage requires new approaches, methods, strategies, and planning for preserving these constructions over time [10].

The renovation of historic buildings requires an integrated and levelled methodology of appraisal and diagnosis as a first step, since the preventive maintenance of historic buildings is a critical issue for a sustainable construction (considering social, economic and cultural values). Concerning the definition of preventive conservation of buildings by Lucchi [11], it can be defined as the periodic condition assessments, early damage detection and planned interventions to minimise deterioration and enable long-term resource efficiency.

Cultural heritage seeks innovative and cost effective tools for systematic monitoring so as to protect and preserve cultural heritage sites or locations, monuments or landscapes. In this framework, gathering data and information for vast areas can be time consuming and expensive, while sometimes the data collection procedure might not be possible due to the lack of the appropriate equipment and tools [12]. Therefore, it is important that the required preservation, conservation and restoration actions of historical monuments are based on detailed studies [13]. Selecting a particular region in South Spain as the case study makes it effective to explore the potential benefits related to preventive maintenance in policies promoting architectural heritage. In general, preventive conservation is generally considered to imply measures to minimize the deterioration and damage of heritage, thus avoiding major restoration interventions and over costs [14].

The proposed innovative tool (Fuzzy Building Service Life adapted to a specific urban context-ART-RISK ${ }_{2.5}$ ) is a new approach based on multidisciplinary analysis of vulnerability and external risks. These kind of tools can help in the city center's development, as it tries to develop global urban preventive conservation strategies capable of minimizing heritage buildings' deterioration and reducing the cost of isolated interventions against hazards through urban plans and preventive conservation programs. Research methodologies based on preventive conservation planning are increasingly used in cultural heritage management, to provide evidences and some guidance to the private or public administrations involved [15]. The approach presented in this paper is a new contribution for the development of conservation policies in built heritage in South Spain, with an approach focused on the recognition of intangible cultural heritage of the city of Seville. The application of the proposed tool is illustrated with case studies which represent religious temples, where the historical and cultural value should be protected and safeguarded, but have been neglected for a long period of time.

This paper presents a simplified tool for the estimation of the functional service life of heritage buildings by non-professional users. The methodology can manage the external risks and vulnerabilities affecting tangible and intangible cultural heritage and including social, economic and environmental criteria. This tool includes a multi-scenario analysis, assessing environmental risks, according to the type of use of the building; moreover, this tool considers static-structural risks together with historical data related with the monuments' life cycle, based on historical records, assessing the degree of vulnerability of the building over time. This information is quite relevant, since it can be applied by different stakeholders within the construction sector and of course can promote an effective and efficient maintenance approach to cultural heritage. 


\section{Materials and Methods}

\subsection{Art-Risk Project}

The tool discussed in this study was developed within the Art-Risk project (https://www.upo. es/investiga/art-risk-en/), which is a RETOS project funded by the Ministry of Economy (Spain) and European Regional Development Fund (ERDF). The main objective of the research project "Artificial intelligence applied to preventive conservation of heritage buildings" (Art-Risk) is to investigate and develop new computerized tools for preventive conservation of heritage in urban centers based on models of artificial intelligence. The project presents a multidisciplinary team specialized in the protection and conservation of heritage, from research institutions in Spain, Portugal, Italy, Romania, Colombia and Chile. The new tool proposed in this project will be available to organizations and companies dedicated to the restoration and rehabilitation of heritage, aiding the adoption of scientific criteria and regional policies for the planning and management of maintenance actions, thus minimizing the risks of losses of cultural assets.

\subsection{Case Studies Analyzed}

The Burra Charter [16] refers the relevance of the protection and conservation of the cultural significance of a local site, due to its historic, scientific, aesthetic and social value. According to this, tangible and intangible heritage stimulate the recognition of certain values that must be protected in a specific context.

This study is based on available data regarding the state of conservation of two tangible religious heritage constructions, Temple of Cruz del Campo and Temple of San Onofre, located in the urban context of the city of Seville, South Spain (Figure 1), which are closely related with intangible social heritage values.

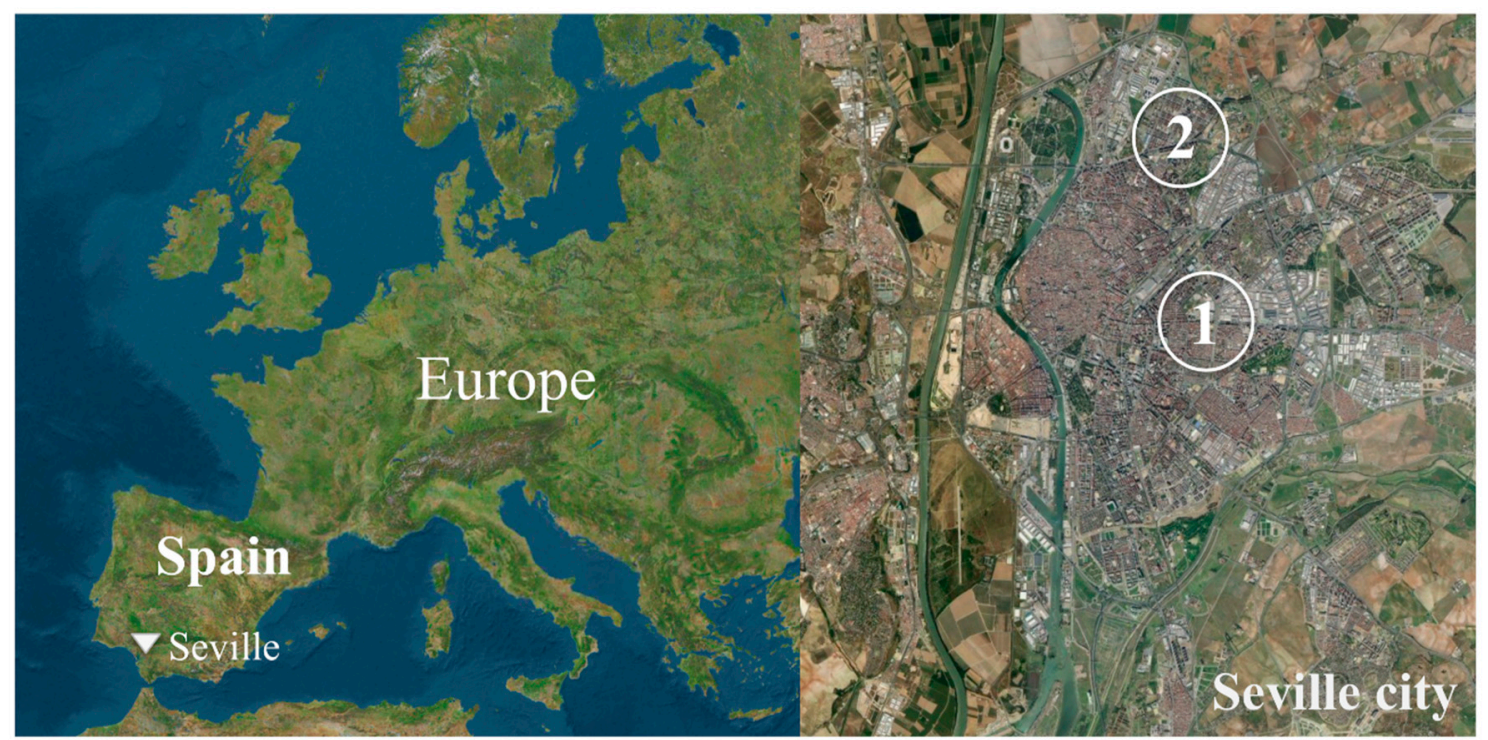

Figure 1. Location of the case studies in South Spain, Seville. Note: 1. Temple of Cruz del Campo: 2. Temple of San Onofre.

The case studies are located in crossroads or street corners, used as a shelter of religious symbols, which was venerated by travelers and pilgrims during their trips. Although these temples were quite common constructions in 15th-18th centuries, nowadays, in the city of Seville, only two temples remain, Temple of San Onofre and Temple of Cruz del Campo (Figure 2). 


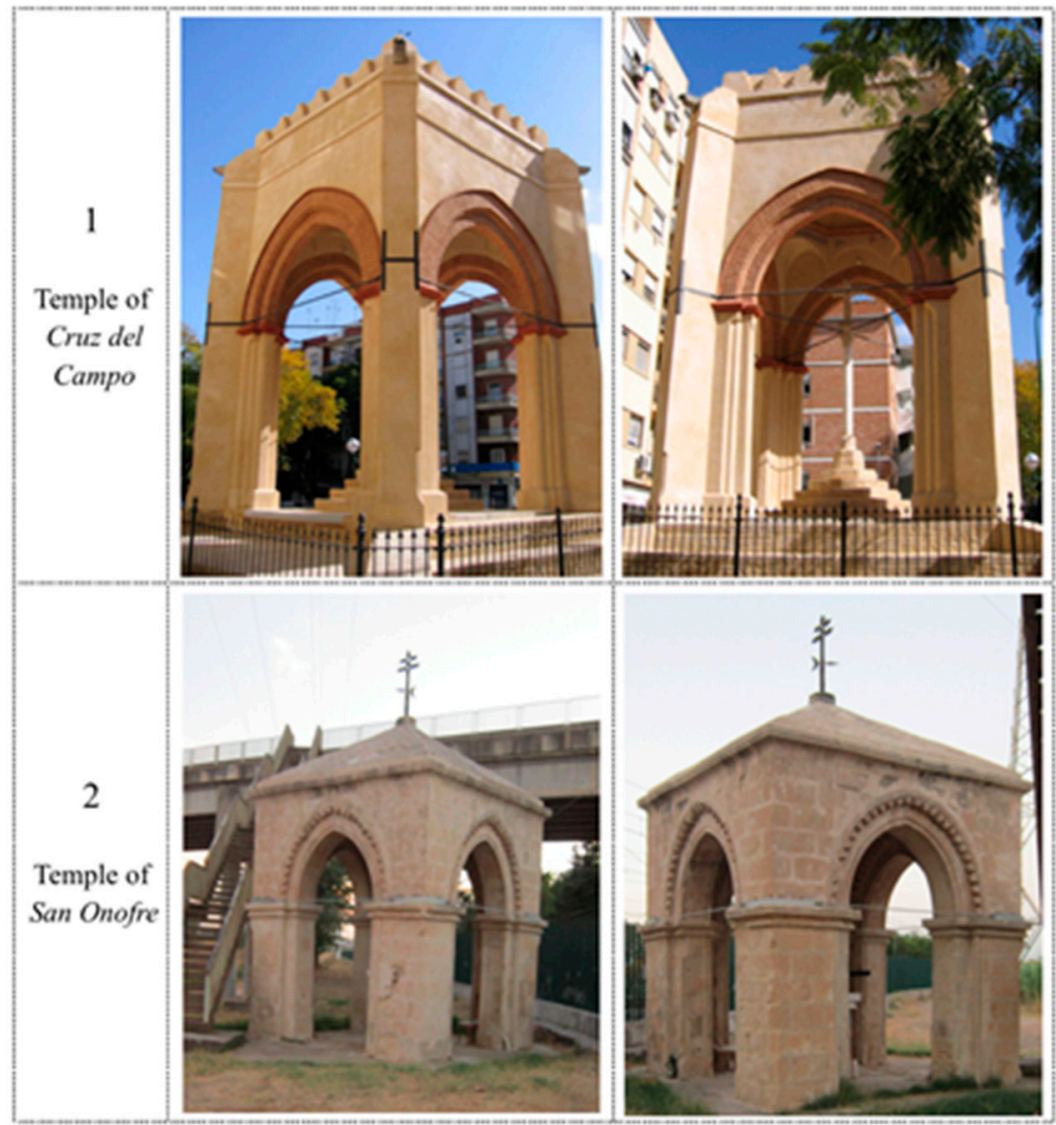

Figure 2. Heritage buildings considered in this study.

\subsubsection{Temple of Cruz del Campo}

\section{- Intangible features. Historical value}

The temple of Cruz del Campo was built around 1380 by the current Brotherhood of 'Los Negritos' from Seville city. This construction is specially linked with the "Via Crucis to the Cruz del Campo". The Via Sacra (or Stations of the Cross) of Seville starts in Pilatos' House, located in the historical city center of Seville and ends in the Temple of Cruz del Campo. This social event was celebrated in the first Friday of each March from 1720 until 1873. Both the Cruz del Campo (tangible cultural heritage) and the Via Crucis (intangible cultural heritage) constituted two decisive elements in the creation of the popular religiousness around the Passion next to liturgical representation [17]. The Cruz del Campo temple helped to forge the current Sevillian Holy Week, one of the most representative religious events in South Europe. The route represents the same distance that Jesus Christ walked from Pilatos' oratorio until Calvary Hill in Jerusalem [18].

\section{- Tangible features. Constructive characterisation}

This heritage building presents four thick columns, which support oval brick arches; the temple shows an interesting set of interior pendentives that turn the square floor into an octagonal dome. The Temple was built entirely of brick, the noblest materials were applied in flared arches, and the rest of the temple was coated by plaster (Figure 2). The upper part of the temple is topped with battlements and blind merlons that reveal the dome behind them [17]. After years of neglect, the building was in a great danger of collapse due to its poor condition. In 2007, the conservation and restoration work of the temple began with the support of Heineken Spain Company and the City Hall of Seville (with a financial contribution of 338, 273€). In March 2008, the temple was reopened, recovering one of the most emblematic symbols of the built heritage of Seville [19]. 


\subsubsection{Temple of San Onofre}

\section{- Intangible features. Historical value}

The Temple of San Onofre was part of the monastery of San Jerónimo and is located in the north urban sector of Seville. This religious monument was built in the real road connection between Cordoba and Seville cities and La Plata Roman road, which connects the South with the North regions of the Iberian Peninsula. Originally, this Temple served several functions, such as reminding pedestrians of religious obligations, ordering traffic, and acting as a reference milestone that marked the arrival at a crossing and even point out the limits of the populations [20]. This temple was a pit stop on the road, and it was associated as a Via Crucis from the city center until here, similarly to the Temple of Cruz del Campo. Currently, this temple is located between a crossroads (railroads, a highway, the Tamarguillo river channel and a regional road) and currently only presents one access through a pedestrian bridge [17].

\section{- Tangible features. Constructive characterisation}

The Temple of San Onofre was discovered inside of another building which was demolished in 1914. The Professor of Art History, Diego Angulo Íñiguez, thoroughly described and documented this temple, dating it in the late fifteenth century, during the reign of the Catholic Monarchs in the Mudejar-Gothic style, still predominant in Western Andalusia in that period [19]. The Temple of San Onofre is a simple construction supported by four columns and it is a hipped building, with pointed Gothic arches including the Islamic influences of Granada (Figure 2). The capitals that support the ribs and the vault key are made with Muqarnas, which is a decorative solution of Persian tradition, brought by Almoravids to Andalusia, South of Spain.

This temple has not been specially conserved despite being listed as an Asset of Cultural Interest and Historical Heritage of Spain. The last restoration was started by ADIF (Railroads infrastructure manager in Spain), owner of part of the land where the constructions is located, with an investment of $25.410 €$. The conservation work began in April 2013 and ended around May-June of the same year [17].

\subsection{Functional Service Life Model Adapted to a Specific Urban Context (ART-RISK 2.5 )}

Fuzzy logic, proposed by L. A. Zadeh [21], is a powerful instrument to be used in the modelling of the real-world phenomena. Fuzzy logic involves conceptualizing the vagueness and uncertainty of complex phenomena, such as the degradation of heritage buildings, into numerical models and crisp quantifiable parameters. Fuzzy logic systems can be adopted for the definition of effective planning of maintenance activities in buildings, providing pragmatic solutions [22]. Previously, within the scope of Art-Risk project, Prieto et al. [23-25] proposed a functional service life model, based on fuzzy logic principles, to prioritize maintenance actions in religious buildings. This extended model (ART-RISK 2.0$)$, previously tested [25], standardized [23] and validated [24]. In this study, the proposed model $\left(A R T-R I S K_{2.5}\right)$ is an adaptation and simplification of that model, considering the particular aspects of the two case studies under analysis.

ART-RISK 2.5 is implemented based on a survey of expert opinion, provided by the previous version (ART-RISK) [26]. A Delphi methodology, applying Opina software, was used to obtain and validate the experts' answers. A total of 15 professionals, with expertise in Architecture, construction and conservation, worked on the model design stage [26]. The fuzzy tool (ART-RISK 2.5$)$ is fully programmed in Java, so it can be executed in most computer systems. The fuzzy adapted model is supported by 10 input variables, four related with the buildings' vulnerabilities and six associated with the risks (static-structural and anthropic risks) (Table 1) $[27,28]$. The fuzzy model was simplified in terms of atmospheric and anthropic risks considering two main reasons: i) the constructions are located in the same city, which presents similar atmospheric conditions; ii) some variables with low impact on the output were removed for helping non-professional users to evaluate the functional degradation 
of heritage constructions (thus reducing the model's complexity and the time required to apply the model). In Figure 3 the hierarchical structure of the adapted fuzzy model is shown. The model is supported by a total of 225 fuzzy inference rules [17].

Table 1. Input factors and description of the valuation of the fuzzy model (ART-RISK 2.5$)$ variables, adapted to the specific context of this study.

\begin{tabular}{|c|c|c|c|}
\hline ID & Input Variables & $\begin{array}{l}\text { Quantitative Value } \\
\text { (Bad/Regular/Good) }\end{array}$ & $\begin{array}{c}\text { Description of the Variables Valuation OF The Functional } \\
\text { Service Life Model Adapted (ART-RISK } 2.5 \text { ) }\end{array}$ \\
\hline$i v_{1}$ & Roof design & $(1.0 / 3.5 / 5.0)$ & Complex and slow/normal/fast evacuation of rainfall water \\
\hline$i w_{2}$ & Preservation & $(1.0 / 3.5 / 5.0)$ & Neglected/normal/optimal state of conservation \\
\hline$i v_{3}$ & Built context & $(1.0 / 3.5 / 5.0)$ & Building between complex or without constructions around it \\
\hline$i v_{4}$ & Constructive system & $(1.0 / 3.5 / 5.0)$ & Heterogeneous or uniform characteristics of the constructive system \\
\hline$i r_{5}$ & $\begin{array}{l}\text { Load state } \\
\text { modification }\end{array}$ & $(1.0 / 3.5 / 5.0)$ & Symmetrical/apparently and disorderly/balanced modification \\
\hline$i r_{6}$ & Overloads & $(1.0 / 3.5 / 5.0)$ & Live load higher/equal/below than the original level \\
\hline$i r_{7}$ & Risk of fire & $(1.0 / 3.5 / 5.0)$ & High/medium/low fire load in relation with a combustible structure \\
\hline$i r_{8}$ & Inner environment & $(1.0 / 3.5 / 5.0)$ & $\begin{array}{l}\text { Maximum/medium/low level of health, cleanliness and hygiene of } \\
\text { the building's spaces }\end{array}$ \\
\hline$i r_{9}$ & Heritage value & $(1.0 / 3.5 / 5.0)$ & Properties with low/average/great historical value \\
\hline$i r_{10}$ & Occupancy & $(1.0 / 3.5 / 5.0)$ & Low/media/high occupancy in the building \\
\hline
\end{tabular}

\begin{tabular}{|c|c|c|c|c|c|c|}
\hline$i v_{1}$ & Roof design & Vulnerability 1 & & & \multirow{10}{*}{$\begin{array}{l}\text { Durability } \\
\text { ( } 25 \text { rules) }\end{array}$} & \multirow{11}{*}{$\begin{array}{c}\text { Output: } \\
\text { Functional } \\
\text { service life } \\
\text { model } \\
\text { adapted } \\
\text { (ART-RISK2.5) }\end{array}$} \\
\hline$i v_{2}$ & Preservation & (25 rules) & Vulnerability & Vulnerability & & \\
\hline$i v_{3}$ & Built context & Vulnerability 2 & (25 rules) & and & & \\
\hline$i v_{4}$ & Constructive system & (25 rules) & & Antritopic & & \\
\hline$i r_{5}$ & Heritage value & Anthropog & nic risks & 5 & & \\
\hline$i r_{6}$ & Occupancy & $(25 \mathrm{ru}$ & les) & (2u & & \\
\hline$i r 7$ & $\begin{array}{l}\text { Load state } \\
\text { modification }\end{array}$ & Structural risks 1 & \multirow{4}{*}{\multicolumn{2}{|c|}{$\begin{array}{l}\text { Global structural risks } \\
\qquad \text { (25 rules) }\end{array}$}} & & \\
\hline$i r_{8}$ & Overloads & (25 rules) & & & & \\
\hline & Fire & Structural risks 2 & & & & \\
\hline$i r_{10}$ & Inner environment & (25 rules) & & & & \\
\hline & $\begin{array}{r}\text { Set of rules } \\
\text { A }\end{array}$ & $\begin{array}{r}\text { Set of rules } \\
\text { B }\end{array}$ & Set of rules & $\begin{array}{r}\text { Set of rules } \\
\text { D }\end{array}$ & Set of rules & \\
\hline
\end{tabular}

Figure 3. Hierarchical structure of the ART-RISK 2.5 fuzzy model.

\section{Results and Discussions}

While the cultural heritage constructions are continuously threatened by anthropogenic and/or natural hazards, local authorities need to prioritize threats and allocate their budget $[12,13]$. In this sense, authorities need to have reliable information regarding the risk status of their cultural heritage. The methodology is focused on the functional degradation condition of cultural heritage with a focus on tangibility and intangibility, as the simplified tools proposed in this study, intending to optimize the authorities' interventions performed in constructions, thus adopting preventive maintenance activities, in order to mitigate and reduce the buildings' progressive functional degradation condition, and thus reducing the risks associated with the failure of these constructions $[29,30]$. ART-RISK 2.5 is an engineering method based on fuzzy logic (artificial intelligence), which helps in the decision-making process of public and private authorities in the preservation of their cultural heritage.

In this study, the functional service-life model based on visual appraisal of the functional anomalies is presented together with the quantification and transposition of the results into the proposed fuzzy inference system. The model is able to classify sets of buildings with homogeneous construction 
features, providing a ranking of constructions with priorities of interventions. Figure 4 shows the application of the proposed model for the analysis of the functional condition of the temples analyzed (Cruz del Campo and San Onofre). A functional degradation condition scale with three possible levels (A, B or C) was established, ranging between Condition A-corresponding to a temple with an acceptable functionality state, Condition B-corresponding to a temple, which requires periodical inspections, in order to maintain the minimal acceptable functional conditions, and finally Condition $\mathrm{C}$-corresponding to a temple in which an adequate functionality level is not guaranteed by the methodology [31].

The application of the proposed model to these two temples leads to the following main conclusions:

The Temple of Cruz del Campo is located inside of the Seville urban mesh and the building represents a historical and social symbol of the neighborhood. However, it is not situated in the historical city center of Seville. This temple, restored in 2008 (five years before of San Onofre's restoration), presents a higher functionality index (76.5 points-Condition A "Building in acceptable functionality state") (Figure 3). Functionality index before intervention was 55.0 points (Condition B "Buildings requires periodical inspections"). However, after a visual in-situ inspection, some anomalies have been found, such as deposition of dirt and debris, staining or color change and some detachment or wearing of the finishing layer;

The Temple of San Onofre is located in a peripheral area of the city, completely disconnected from the population flows. Currently, the heritage construction is isolated, as previously described, and only a stair from the regional road connects the building by local pedestrians. As Nicu [32] remarks, nowadays, the anthropogenic pressure has become higher and higher due to the expansion of human settlements and the need of connecting them, and this has been identified as being one of the most dangerous factors that are affecting the integrity and value of the heritage constructions under analysis.

In Figure 2 the emplacement characterization of the building is shown. In Figure 4, in 2012, the Temple of San Onofre was practically abandoned, completely covered by parasitic vegetation and presenting different anomalies associated with stone rocks degradation, such as loss of integrity, lack of linearity between the joints of stone plates, materials loss, biological growth, efflorescence, stains, among others. According to the proposed model (ART-RISK 2.5$)$, the functionality condition before intervention (in 2012) was around 34.0 points (Condition C), revealing that the functionality of the temple was below acceptable performance levels (the functionality is not warrantied).

After the intervention focused on the restoration of the Temple of San Onofre, with an investment of $25,410 €$, the current functional degradation index of this case study is around 55.5 points (Condition B "Buildings requires periodical inspections") (Figure 4). The intervention was not able to improve the temple's functionality to the highest condition, mainly due to the severe degradation condition observed before intervention, the small investment applied in the renovation of the temple and due to the external risks influenced by the location of the temple. It is necessary to remark that the isolated location and the extreme difficulties in terms of the access to this construction, which can be clearly seen as one of the factors, affects the current state of conservation.

Both temples are relevant, in a social and religious point of view, for the inhabitants of neighborhood-city, and the recent restoration of both confirm this assumption. Although the Temple of San Onofre was restored in 2013, it presents a lower functionality index than the Temple of Cruz del Campo, which was restored in 2008. The funds used for the interventions, 338,273€ for Temple of Cruz del Campo and 25,410€ for Temple of San Onofre, proved to be crucial to the functionality condition of the temples. The location of the temples is a fundamental matter in this sense, since San Onofre's Temple presents greater vulnerability conditions associated with several variables: the conditions of isolation and lack of adequate access hinder the relationship of the heritage asset with the society that surrounds it. As it is established by Nicu [8], before the construction of a road, an initial assessment should be needed, which should include a public consultation. This kind of action should prevent isolated locations such as the current location of the Temple of San Onofre. 


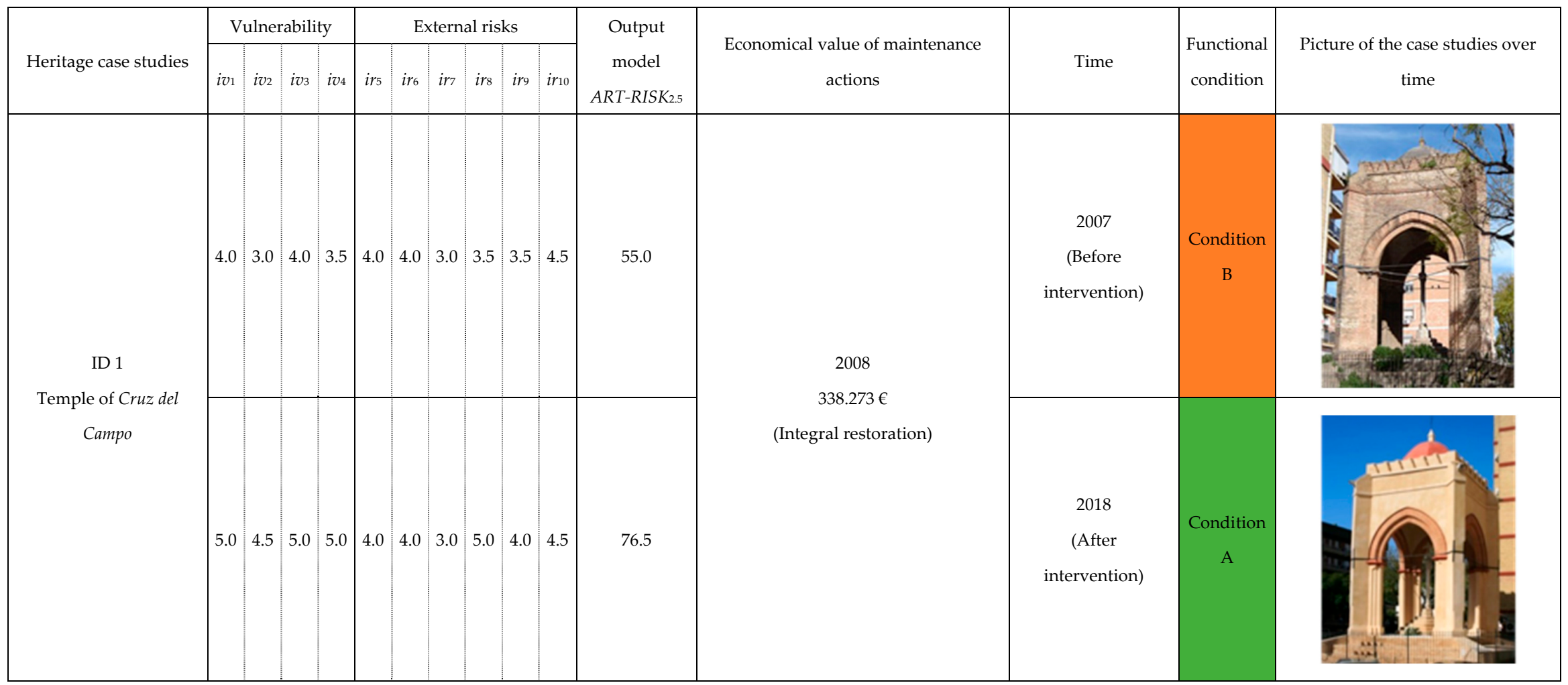

Figure 4. Cont. 


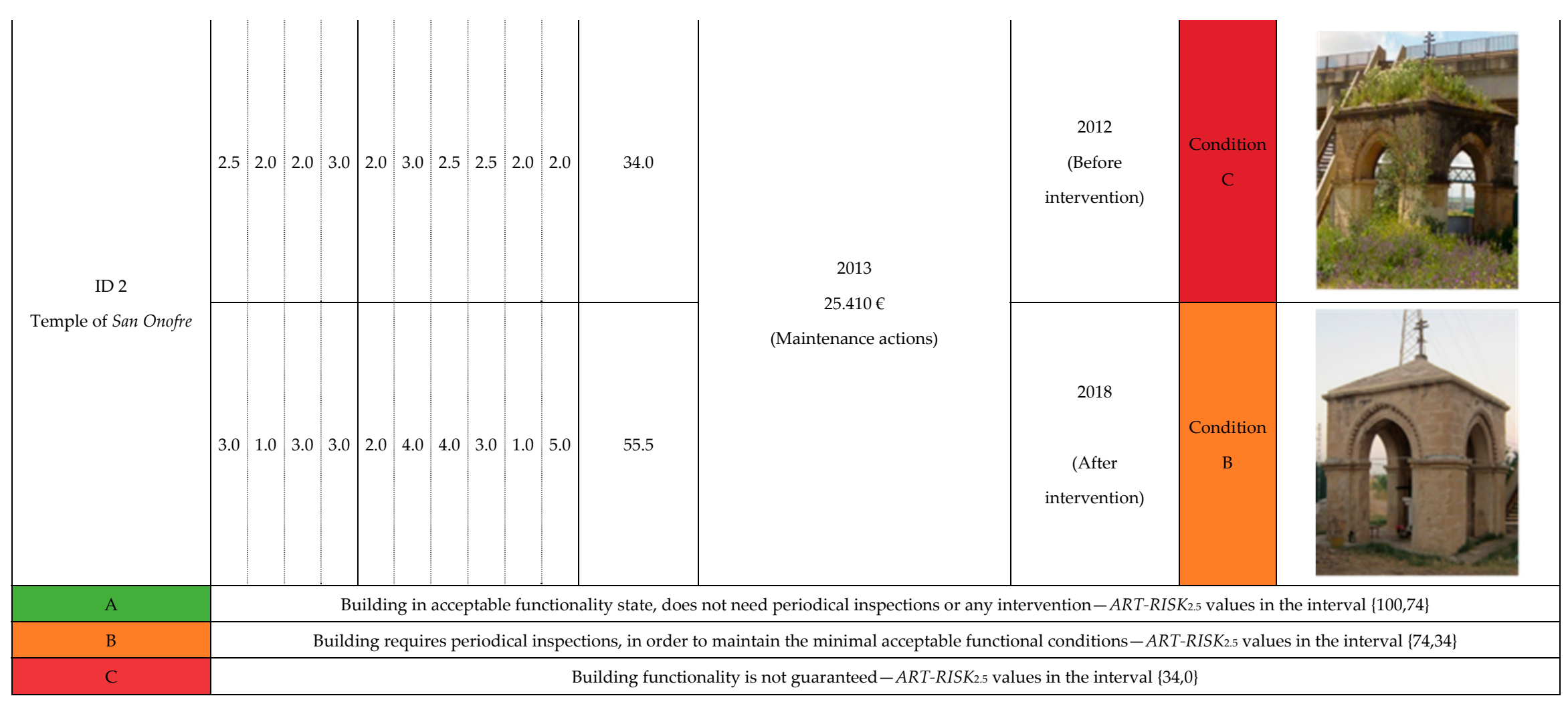

Figure 4. Functional degradation condition before and after interventions of the temples analyzed in Seville (South Spain). 
Concerning the methodology applied (ART-RISK 2.5$)$, the proposed model seems to coherently describe the functionality level of the temples under analysis. This new approach encompasses the relevant variables related with the buildings' vulnerability and external risks, evaluating the functional condition of heritage buildings based on social, economic and environmental factors associated to a particular context. This information can be very useful in terms of the definition of future preventive conservation plans [33]. The adoption of successful future preventive maintenance actions can only be achieved through the analysis of previous activities in heritage constructions, identifying previous maintenance works and the effects of these actions on the functional performance of these buildings.

This fuzzy logic model is a new contribution for the implementation of new approaches for preventive maintenance actions applied to built heritage in historical cities, promoting the sustainable urban development based on functional criteria [34]. Moreover, the major simplification of the interface allows non-specialized users to evaluate the functional degradation condition of cultural heritage buildings. In fact, with the adequate adaptations, the proposed model can be easily implemented in other religious buildings outside of Seville region and to other sets of buildings with homogeneous constructive characteristics.

\section{Conclusions and Future Research Lines}

This study proposed an innovative application of an engineering model based on fuzzy logic (artificial intelligence) to evaluate tangible and intangible features in the functional condition of two heritage constructions (religious temples) in the location of Seville, South Spain. The functional degradation condition (vulnerability and external hazards) was put together with an analysis of visual anomalies degradation and considering social, economic and environmental variables. Despite the fact that the buildings are under the protection by the Asset of Cultural Interest and Historical Heritage standard of Spain, the Temple of San Onofre, restored in 2013, presents a medium functionality state (Condition B-Building requires periodical inspections, in order to maintain the minimal acceptable functional conditions). The isolation of the building and the lack of adequate access hinder the relationship of the heritage asset with the society that surrounds it.

However, the Temple of Cruz del Campo, restored in 2008 (five years before the Temple of San Onofre), presents a good functionality state (Condition A-Building in acceptable functionality state, do not need periodical inspections or any intervention). The results obtained by the model are coherent with the observed reality, and are mainly due to the following reasons: (i) the location of the constructions inside of the city urban mesh and the day-to-day relationship between the building and local population, (ii) the economical investment was unequal for each case study, leading to a higher functional level for the building with the highest investment, (iii) the management of political actions related with the preservation of the building and consequently, the funds invested in the maintenance actions, are strongly linked with the social value of the temple. There exists a significant relationship between anthropic external hazards and the role that humans play in it; being strongly interconnected, there should exist more efforts focused on the mitigation of the anthropic pressure or influence over the cities landscape and their environment.

The fuzzy logic model proposed in this study can help in the systematization of maintenance interventions in terms of decision making by stakeholders. The automation of interventions and maintenance actions can reduce the consumption of natural resources, allowing more-rational management of future maintenance operations in cultural heritage.

The ART-RISK 2.5 tool could be very useful for stakeholders (public and private administrations) and non-specialized users, as an important reference on diagnosis, including updated, inexpensive and sustainable methodologies to manage the preservation of monuments, which are easy to use in developed and developing countries. This study is the first application of this model in this particular context, which remarks the versatility of the methodology, when a set of constructions with homogeneous constructive characteristics is examined. This kind of approach has made it possible to 
determine and protect intangible cultural heritage (which was previously neglected for a long period of time) as heritage to be preserved and safeguarded.

In future works, the inclusion of these results into Geographic Information System (GIS) environments would increase the knowledge on functional degradation condition of architectural heritage sets in the local context. Currently, this aspect is under development in Art-Risk Project, and this information could help national, regional and local public administrations, providing tools that not only enhance the digitalization of information but that also generate new knowledge in preventive maintenance of cultural heritage.

Author Contributions: A.J.P., J.M.M.-B., A.S. and P.O. took part in the entire researching process.

Funding: This research was funded the Research Project ART-RISK, a RETOS project of Ministry of Economy and Competitiveness, Spain and European Regional Funds Development (ERFD), (code: BIA2015-64878-R (MINECO/FEDER, UE).

Acknowledgments: The authors gratefully acknowledge the support of Núcleo de Investigación en Riesgos Naturales y Antropogénicos (RiNA), Institute of Architecture and Urbanism, Faculty de Architecture and Arts, Universidad Austral de Chile, Valdivia, Chile. This paper has been supported and based on the Methodology developed by the Research Project ART-RISK, a RETOS project of Ministry of Economy and Competitiveness, Spain and European Regional Funds Development (ERFD), (code: BIA2015-64878-R (MINECO/FEDER, UE)). The authors also gratefully acknowledge the support of the CERIS-ICIST Research Institute, IST, University of Lisbon, Portugal.

Conflicts of Interest: The authors declare no conflict of interest.

\section{References}

1. Ibrahim, F.; Harun, S.H.; Samad, A.; Hanim, M.; Harun, W.; Mariah, W. Interior Semantics Of The Lobby/Waiting Area In General Hospitals; A Preliminary Study. Presented at the 2nd International Conference on Built Environment in Developing Countries 2008, Penang, Malaysia, 3-4 December 2008.

2. Wai-Yin, C.; Shu-Yun, M. Heritage preservation and sustainability of China's development. Sustain. Dev. 2004, 12, 15-31. [CrossRef]

3. Ipekoglu, B. An architectural evaluation method for conservation of traditional dwellings. Build. Environ. 2006, 41, 386-394. [CrossRef]

4. Amit-Cohen, I.; Sofer, M. Cultural heritage and its economic potential in rural society: The case of the kibbutzim in Israel. Land Use Policy 2016, 57, 368-376. [CrossRef]

5. Nicu, I.C.; Stoleriu, C.C. Land use changes and dynamics over the last century around churches of Moldavia, Bukovina, Northern Romania-Challenges and future perspectives. Habitat Int. 2019, 88, 101979. [CrossRef]

6. Godfrey, A.; Ciurean, R.L.; Van Westen, C.J.; Kingma, N.C.; Glade, T. Assessing vulnerability of buildings to hydro-meteorological hazards using an expert based approach-An application in Nehoiu Valley, Romania. Int. J. Disaster Risk Reduct. 2015, 13, 229-241. [CrossRef]

7. Fuchs, S. Susceptibility versus resilience to mountain hazards in Austria-Paradigms of vulnerability revisited. Nat. Hazards Earth Syst. Sci. 2009, 9, 337-352. [CrossRef]

8. Nicu, I.C. Tracking natural and anthropic risks from historical maps as a tool for cultural heritage assessment: A case study. Environ. Earth Sci. 2017, 76, 330. [CrossRef]

9. Sadegui, N.; Fayek, A.R.; Seresht, N.G. Queue performance measures in construction simulation models containing subjective uncertainty. Autom. Constr. 2015, 60, 1-11. [CrossRef]

10. Vicente, R.; Ferreira, T.M.; Mendes da Silva, J.A.R. Supporting urban regeneration and building refurbishment, strategies for building appraisal and inspection of old building stock in city centres. J. Cult. Herit. 2015, 16, 1-14. [CrossRef]

11. Lucchi, E. Review of preventive conservation in museum buildings. J. Cult. Heritage 2018, 29, 180-193. [CrossRef]

12. Agapiou, A.; Lysandrou, V.; Alexakis, D.; Themistocleous, K.; Cuca, B.; Argyriou, A.; Sarris, A.; Hadjimitsis, D. Cultural heritage management and monitoring using remote sensing data and GIS: The case study of Paphos area, Cyprus. Comput. Environ. Urban Syst. 2015, 54, 230-239. [CrossRef]

13. Hadjimitsis, D.; Agapiou, A.; Alexakis, D.; Sarris, A. Exploring natural and anthropogenic risk for cultural heritage in Cyprus using remote sensing and GIS. Int. J. Digit. Earth 2013, 6, 115-142. [CrossRef] 
14. Cebron Lipovec, N.; Van Balen, K. Preventive conservation and maintenance of architectural heritage as means of preservation of the spirit of place. In 16th ICOMOS General Assembly and International Symposium: Finding the Spirit of Place-Between the Tangible and the Intangible; UNESCO: Paris, France, 2008.

15. Jones, S. Experiencing authenticity at heritage sites: Some implications for heritage management and conservation. Conserv. Manag. Archaeol. Sites 2009, 11, 133-147. [CrossRef]

16. Truscott, M.; Young, D. Revising the burra charter: Australia ICOMOS updates its guidelines for conservation practice. Conserv. Manag. Archaeol. Sites 2000, 4, 101-116. [CrossRef]

17. Prieto, A.J. Modelado de la Vida Útil de Edificios Patrimoniales Analizando Variables de Vulnerabilidad y Riesgos en Edificios Patrimoniales. Master's Thesis, University of Seville, Sevilla, Spain, 2013. (In Spanish).

18. González-Moreno, J. Vía Crucis a la Cruz del Campo; Editorial Castillejo: Sevilla, Spain, 1992.

19. De Mena, J.M. Historia de Sevilla; Penguin Random House Grupo Editorial España: Barcelona, Spain, 2011; ISBN1 8401347645. ISBN2 9788401347641. (In Spanish)

20. IAPH. Instituto Andaluz de Patrimonio Histórico (Andalusian Movable Heritage). 2017. Available online: http://www.iaph.es/patrimonio-mueble-andalucia/resumen.do?id=186154 (accessed on 20 June 2019).

21. Zadeh, L. Fuzzy sets. Inf. Control. 1965, 8, 338-353. [CrossRef]

22. Silva, A.; de Brito, J.; Gaspar, P.L. Methodologies for service life prediction of buildings. With a focus on façade claddings. In Green Energy and Technology; Springer: Berlin, Germany, 2016. [CrossRef]

23. Ibáñez, A.J.P.; Bernal, J.M.M.; Chávez-De-Diego, M.-J.; Sánchez, F.J.A.; Prieto, A. Expert system for predicting buildings service life under ISO 31000 standard. Application in architectural heritage. J. Cult. Heritage 2016, 18, 209-218. [CrossRef]

24. Prieto, A.J.; Macías-Bernal, J.M.; Chávez, M.-J.; Alejandre, F.J. Fuzzy modeling of the functional service life of architectural heritage buildings. J. Perform. Constr. Facil. 2017, 31, 4017041. [CrossRef]

25. Prieto, A.J.; Silva, A.; de Brito, J.; Macías-Bernal, J.M. Serviceability of facade claddings. Build. Res. Inf. 2018, 46, 179-190. [CrossRef]

26. Bernal, J.M.M.; Calama-Rodríguez, J.M.; Chávez-De-Diego, M.-J. Modelo de predicción de la vida útil de la edificación patrimonial a partir de la lógica difusa. Informes de la Construcción 2014, 66, 006.

27. Ortiz, P.; Antunez, V.; Martín, J.M.; Ortiz, R.; Vázquez, M.A.; Galán, E. Approach to environmental risk analysis for the main monuments in a historical city. J. Cult. Heritage 2014, 15, 432-440. [CrossRef]

28. Ortiz, R.; Ortiz, P. Vulnerability Index: A new approach for preventive conservation of monuments. Int. J. Arch. Heritage 2016, 10, 1078-1100. [CrossRef]

29. Romão, X.; Paupério, E.; Pereira, N. A framework for the simplified risk analysis of cultural heritage assets. J. Cult. Heritage 2016, 20, 696-708. [CrossRef]

30. Revez, M.J.; Rodrigues, J.D. Incompatibility risk assessment procedure for the cleaning of built heritage. J. Cult. Heritage 2016, 18, 219-228. [CrossRef]

31. Prieto, A.J.; Vásquez, V.; Silva, A.; Horn, A.; Alejandre, F.J.; Macías-Bernal, J.M. Protection value and functional service life of heritage timber buildings. Build. Res. Inf. 2017, 47, 567-584. [CrossRef]

32. Nicu, I.C. Cultural heritage assessment and vulnerability using analytic hierarchy process and geographic information systems (Valea Oii catchment, North-eastern Romania). An approach to historical maps. Int. J. Disaster Risk Reduct. 2016, 20, 103-111. [CrossRef]

33. Carter, R.W.; Bramle, R. Defining heritage values and significance for improved resource management: An application to Australian tourism. Int. J. Heritage Stud. 2002, 8, 175-199. [CrossRef]

34. Tweed, C.; Sutherland, M. Built cultural heritage and sustainable urban development. Landsc. Urban Plan. 2007, 83, 62-69. [CrossRef]

(C) 2019 by the authors. Licensee MDPI, Basel, Switzerland. This article is an open access article distributed under the terms and conditions of the Creative Commons Attribution (CC BY) license (http://creativecommons.org/licenses/by/4.0/). 